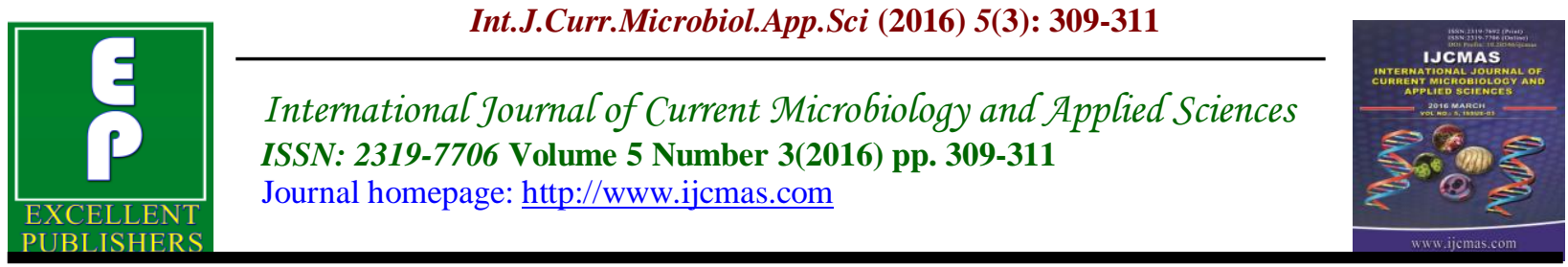

Case Study

http://dx.doi.org/10.20546/ijcmas.2016.503.037

\title{
Brucellosis: An Under Diagnosed Zoonosis
}

\author{
U. Pratibha Bhat* and A. Asha \\ Department of Microbiology, K S Hegde Medical Academy, Mangaluru 575018, India \\ *Corresponding author
}

\section{Keywords \\ Brucellosis, Misdiagnosis, Pyrexia of unknown origin.}

\section{Article Info}

Accepted:

15 February 2016

Available Online:

10, March 2016

\section{A B S T R A C T}

Brucellosis is an important, but neglected cause of pyrexia of unknown origin. It is a severely debilitating condition and also causes great economic losses. Diagnosis of brucellosis is difficult. Hence the medical and laboratory staff needs to be alert to recognise this condition. We report a case of brucellosis which reflects the same.

\section{Introduction}

Brucellosis is an economically important zoonotic disease. It is caused by bacteria of the genus Brucella, namely, Brucella melitensis, B. abortus, B. suis and rarely by B. canis. This condition has got a worldwide distribution, being more common in countries where livestock rearing is predominant (Winn W et al., 2006). Based on previous studies, seroprevalence of human brucellosis in India varies widely from $0.8 \%$ to $26.6 \%$. The true incidence may be much more as the condition is grossly neglected (Kadri SM et al., 2000, Yohannes M and Gill JPS, 2011).

Brucellosis is a cause of pyrexia of unknown origin (PUO) and can lead to complications like neurobrucellosis, arthritis, endocarditis, respiratory tract infections (Winn et al.,
2006; Chahota et al., 2015; Starakis I et al., 2010). We present a case report which stresses the need for brucellosis being a differential diagnosis in cases of fever of one week or more duration.

\section{Case Report}

A 57 year old male patient, presented to a tertiary care centre with a history of fever, myalgia, cough since 1 week. Sputum was scanty, mucoid and not blood tinged. There was no history of abdominal pain, diarrhoea or burning micturition. On examination, his pulse rate was82beats/min and BP$110 / 70 \mathrm{mmHg}$. Throughout his hospital stay he was afebrile except on one occasion a temperature of $100^{\circ} \mathrm{F}$ was recorded. His systemic examination was normal. A 
preliminary diagnosis of enteric fever was made and investigations were sought for.

His total WBC count was 8000cells $/ \mathrm{mm}^{3}$ with differential count showing relative lymphocytosis (neutrophils-52\%, lymphocytes-47\%, eosinophils-1\%), platelet count was $2,80,000 / \mathrm{mm}^{3}$ and ESR was $17 \mathrm{~mm} / \mathrm{hr}$. Liver function tests were within normal limits with total bilirubin $0.6 \mathrm{mg} / \mathrm{dl}$, SGOT-26U/L, SGPT-37U/L. Workup of fever was done with Widal test, dengue card test, leptospira card test and malarial QBC test. All the tests were negative. Blood sample was cultured in the automated blood culture system, BacT Alert which was negative after 48 hours of incubation. Empiric therapy with injection ceftriaxone $1 \mathrm{gm}$ BD was given for 2 days and later changed to oral cefixime $200 \mathrm{mg}$ BD for 2 days. The patient was discharged on the $4^{\text {th }}$ day of admission with a diagnosis of enteric fever and advised oral cefixime 200mg BD for 3 days and multivitamin capsules for 2 weeks. He was advised for review in OPD after 2 weeks.

The blood culture system flagged positive after 4 full days of incubation. Gram staining showed small gram negative coccobacilli arranged in singles and groups. Growth was obtained on solid media which was subsequently identified as Brucella abortus based on the conventional biochemical reactions.

It was nonmotile, catalase positive, oxidase positive, growth enhanced by $\mathrm{CO}_{2}$, urea hydrolysed rapidly, decarboxylation of aminoacids, nonfermentor of carbohydrates. Microbiological diagnosis was further supported by a positive Brucella agglutination test in the serum sample, titre being 640. But the patient was lost for follow up. History of mode of transmission and the source of infection could not be elicited.

\section{Results and Discussion}

Brucellosis is often overlooked due to the nonspecific clinical presentation and inappropriate utilisation of laboratory testing methods. Brucellosis should be considered as an important cause of fever of unknown origin. The most definitive test for the diagnosis of brucellosis is blood culture. But they are positive only in 30-50\% of the cases and also have a disadvantage of slow growth. Conventional blood cultures have to be incubated for a period of 8 weeks (Farell ID, 2006). Automated cultures may yield growth in 5-6 days. As cultures are often negative serological tests are important in the diagnosis. Antibodies to Brucella appear 7-10days after the onset of infection. Various serological tests are available like rose Bengal card test (RBT), Brucella Standard Agglutination Test (SAT), Brucella IgM/IgG ELISA. ELISA Test for IgM and $\mathrm{IgG}$ antibodies is more sensitive. Serological tests havethe advantage of quicker results (Sathyanarayan et al., 2011).

Brucellosis may be acquired by consumption of unpasteurised milk and dairy products, eating infected raw meat, direct contact with animals via skin and conjunctiva and by inhalation of aerosols (Smits HL and Kadri SM, 2005). So people engaged in occupations involving animals are at risk. This stresses the importance of elicitation of occupational history.

Brucellosis can be effectively treated with good outcomes. Recommended treatment is a combination of doxycycline with either streptomycin, rifampicin or cotrimoxazole (Alavi SM and Alavi L, 2013).

In the present case, timely diagnosis of brucellosis would have been possible, if a Brucella agglutination test had been sought for and the patient could have been treated accordingly. Early diagnosis of brucellosis is 
possible with a high index of suspicion, proper elicitation of history and appropriate and timely investigations.

\section{References}

Alavi, S.M., Alavi, L. 2013. Treatment of brucellosis: a systematic review of studies in recent twenty years. Caspian J. Int. Med., 4(2): 636-41.

Chahota, R., Dattal, A., Thakur, S.D., Sharma, M. 2015. Isolation of Brucella melitensis from a human case of chronic additivepolyarthritis. Ind. J. Med. Microbiol., 33: 429-32.

Farell, I.D., Brucella. 2006. In Mackie and McCartney Practical medical Microbiology, editors Collee J.G, Fraser A.G, Marmion B.P, Simmons A, $14^{\text {th }}$ ed. Churchil Livingstone Elsevier. pp. 473-78.

Kadri, S.M., Rukhsana, A., Laharwal, M.A., Tanvir, M. 2000. Seroprevalence of brucellosis in Kashmir (India) among patients with pyrexia of unknown origin. J. Ind. Med. Association, 98(4): 170-71.
Sathyanarayan, M.S., Suresh, D.R., Suresh, B.S., Krishna, S., et al. 2011. A comparative study of agglutination tests, blood culture and ELISA in the laboratory diagnosis of brucellosis. Int. J. Biol. Med. Res., 2(2): 569-72.

Smits, H.L., Kadri, S.M. 2005. Brucellosis in India: a deceptive infectious disease. Ind. J. Med. Res., 122: 375-84.

Starakis, I., Mazokopakis, E.E., Bassaris, H. 2010. Unusual manifestations of brucellosis: a retrospective case series in a tertiary care Greek University Hospital. EMHJ., 16(4): 365-70.

Winn, W., Allen, S., Janda, W., Koneman, E., Procip, G., Schrekenberger, P., et al 2006. Miscellaneous fastidious gram negative bacilli chap 9. In Koneman's color atlas and textbook of diagnostic microbiology, $6^{\text {th }}$ ed. Philadelphia: Lippincott Williams and Wilkin, pp. 483-90.

Yohannes, M., Gill, J.P.S. 2011. Seroepidemiological survey of human brucellosis in and around Ludhiana, India. Emerging Health Threats J., 4: 7361. Doi: 10.3402/ehtj.v4i0.7361.

\section{How to cite this article:}

Pratibha Bhat, U., Asha, A. 2016. Brucellosis: An Under Diagnosed Zoonosis. Int.J.Curr.Microbiol.App.Sci. 5(3): 30-311. doi: http://dx.doi.org/10.20546/ijcmas.2016.503.037 